\title{
Correction to: Unpacking domestic preferences in the policy-'receiving' state: the EU's migration cooperation with Senegal and Ghana
}

\author{
Melissa Mouthaan
}

Correspondence: mIm62@cam.ac.uk The original article can be found online at https://doi.org/10.1186/s4 0878-019-0141-7

Centre of Development Studies, Department of Politics and International Studies, University of Cambridge, Alison Richard Building, 7 West Road, Cambridge CB3 9DT, UK

\section{Correction to: Comparative Migration Studies}

https://doi.org/10.1186/s40878-019-0141-7

In the original publication of this article (Mouthaan, 2019), the last section heading has been processed incorrectly as 'List of interviews' instead of 'Conclusion'. The original publication of this article has been corrected.

The publisher apologises to the author and readers for the inconvenience.

Published online: 09 September 2019

\section{Reference}

Mouthaan, M. (2019). Unpacking domestic preferences in the policy-'receiving' state: the EU's migration cooperation with Senegal and Ghana. Comparative Migration Studies, 7. https://doi.org/10.1186/s40878-019-0141-7. 